\title{
Knowledge and attitudes of primary care nurses and midwives towards health promotion in rural South Africa
}

\author{
K Peltzer, Health Behaviour Research Unit,University of the North
}

\section{Abstract}

This study was designed to study knowledge, attitudes and views about health promotion among nurse clinicians in rural South Africa. The sample included 90 nurse clinicians ( 73 primary health care nurses and 17 midwives) in the age range of 24 to 59 years ( $M$ age $38.4 \mathrm{yr}$, $S D=9.3$ ) in the Northern Province. Results indicate that nurses $(66.6 \%)$ had an inadequate knowledge score on health promotion in this sample. Higher knowledge scores on health promotion were not associated with age and years of experience. However, male nurses had significantly higher knowledge scores on health promotion than female nurses. The majority strongly supported the centrality of their role in health promotion acknowledging the time constraints involved. Better knowledge on health promotion was associated with more positive views on health promotion. More nurses had a satisfactory positive attitude towards health promotion (63.3\%) than knowledge about health promotion (33.3\%). Finally, the study found that compliance with health promotion was seen as a problem but health counselling was nevertheless seen as cost effective.

\section{Introduction}

The proportion of deaths due to chronic diseases of lifestyle was responsible for $24.5 \%$ of all deaths of all South Africans and $28.5 \%$ of those aged 35-64 years. The major causes of death contributing to these figures were cerebrovascular diseases $(7.2 \%$ of all deaths) and ischaemic heart disease $(8.7 \%$ of all deaths). Overall 4.88 million South Africans smoked, the largest group of smokers being Black males (2.6 million). For hypertension 5.5 million South Africans had pressure above 140/90 $\mathrm{mmHg}$; again the largest group were Blacks (3.0 million). For hypercholesterolaemia and raised low-density lipoprotein cholesterol levels, 4.8 million and 3.1 million South Africans respectively had an increased risk for ischaemic heart disease, Blacks having the lowest levels (Bradshaw, Bourne, Schneider \& Sayed 1995: 6ff.). In a recently nationally representative survey the Medical Research Council (1998) found that among persons above 15 years $11 \%$ of men and $13 \%$ of women were found to either have a blood pressure above $160 / 95 \mathrm{mmHg}$ or were taking appropriate medication to lower their blood pressure. A calculation based on these prevalence rates and the census figures published for the South African population 15 years and older leads to an estimate of about 3.3 million hypertensive people in the country. While the full etiology of any of these diseases has yet to be understood, behavioural factors such as tobacco use, exercise, diet, alcohol consumption and preventive health checks are strongly implicated as risk factors (Steptoe \& Wardle 1992: 486f.). These behavioural factors are subject to behaviour change and health promotion.

Health promotion is the process of enabling people to increase control over and improve their health. To reach a state of complete physical, mental and social well-being, an individual or group must be able to identify and to realise aspirations, to satisfy needs, and to change or cope with the environment. Health is seen as a resource for everyday life, not the objec- tive for living. Health is a positive concept emphasising social and personal resources, as well as physical capacities. Therefore, health promotion is not just the responsibility of the health sector. It goes beyond healthy life-styles to the wellbeing of people. To achieve health promotion the Ottawa Charter outlined five health promotion strategies: (1) building healthy public policy, (2) creating supportive environments, (3) strengthening community action, (4) developing personal skills, and (5) reorienting health services. The latter two include: health promotion supports personal and social development by providing information, education for health, and enhacing skills to take control over their own health and environment. This has to be facilitated in school, home, work and community settings. The responsibilty for health promotion in health services is shared among individuals, community groups, health professionals, health service institutions and government. The role of the health sector must move increasingly in a health promotion direction, beyond its responsibility for providing clinical and curative services. This mandate should support the needs of individuals and communities for a healthier life (WHO 1986: 5-8). The Jakarta Declaration on Health Promotion (1997) offers strategies for health promotion in the $21^{\text {st }}$ century: (1) promote social responsibility for health, (2) increase investment for health development, (3) consolodate and expand partnerships for health, (4) increase community capacity and empower the individual, and (5) secure an infrastructure for health promotion (Norton 1998: 1270). The World Health Organisation (1999) puts emphasis on primary health care of which two of the eight elements address health promotion: education on prevailing health problems and methods of preventing and controlling them, and, prevention and control of locally endemic diseases.

In the new South Africa (after independence) much emphasis has been placed on primary health care, and health promotion has been identified as central to the success of primary 
health care (Coulson, Goldstein \& Ntuli, 1998: 21). Primary health care services are provided free of charge consisting of a broad scope of health care: treatment of common diseases and minor injuries, education concerning prevailing health problems in the community and methods of preventing and controlling them, maternal-child health services, family planning, immunizations, prevention and control of locally endemic diseases, and assistance with initiating health promotion activities. The White Paper on Health Systems Transformation emphasises the development of health promotion practices (Department of Health 1997: 1f.). Coulson (1999: 5f.) notes that health promotion in South Africa is weak, poorly documented, unco-ordinated and lacking in capacity. The national health promotion policy in draft form has the aims of (1) Put health promotion on the map; (2) Promote the approach described in the Ottawa Charter; (3) Promote the settings approach for South Africa especially Healthy Schools; (4) To identify the scope of activity of health promotion; (5) To outline the functions at provincial, regional and district levels. There are four major approaches to health promotion adopted in South Africa: (1) Policy, advocacy and healthy environments; (2) The settings approach; (3) Education and information; (4) Re-orienting health services and community participation. In terms of the core package of primary health care services, health promotion is considered a community service. This implies that health promotion should involve outreach work into health districts. Given the pressures on nurses to become the new primary health care practitioners with diagnosing and despensing skills, the space for outreach community work in their busy schedules is unlikely (Coulson 1999: 8ff.).

The role of the nurse as an agent in health promotion has been legitimized by the World Health Organization (1986: 4ff.). Sourtzi (1998: 9) found among community nurses in Greece that they incorporated health promotion in their everyday practtice, but it seemed that there was a need for further advancement in their understanding in order to improve their practice, and it was suggested that education at both pre- and post- registration levels should therefore include health promotion not as an area of practice only but as a core concept. Steptoe, Doherty, Kendrick, Rink and Hilton (1999: 158) found among general practitioners and practice nurses in Britain that practice nurses were seen to have the main responsibility for cardiovascular health promotion. Although attitudes to health promotion were generally positive, lack of training in lifestyle counselling was perceived to be a problem. Few responders believed that they were influential in helping people change their lifestyles. Beliefs about the effectiveness of lifestyle counselling were mixed, with cigarette smoking, physical inactivity and obesity being seen as difficult to change. Beliefs in the effectiveness of lifestyle counselling were associated with positive attitudes towards health promotion and greater confidence in training. Whitehead (2001: 822) noted that nurses are often unaware of the extremely complex human phenomena associated with modifying health-related behaviours and the resultant change processes.

There is a lack of studies in South Africa relevant to health promotion among nurses, and there is a need for exploring the knowledge, practice, attitudes of primary care nurses and midwives regarding health promotion.

Therefore, the objectives of this study were to assess (1) nurses' knowledge about health promotion, (2) nurses' attitudes to- wards health promotion of specific lifestyles, (3) nurses' views regarding responsibility of health promotion, and (4) views of nurses about clients' responses to health promotion and health education efforts.

\section{Methods Design}

The study is an interview-administered survey using a twostage cluster sampling of nurse clinicians and midwives.

\section{Sample and procedure}

The sample included 90 nurse clinicians in the Northern Province of South Africa.

Twenty-five clinics were randomly sampled using random digits from a total number of 394 clinics (excluding mobile clinics) in the province. From each clinic four nurse clinicians were selected on a particular working day by convenience. Some clinics did not have four nurse clinicians, therefore the total number of interviewed nurse clinicians reduced from 100 to 90 .

Approval to conduct the study was given by the Ethics Committee of the University of the North and the Northern Province Department of Health and Welfare. Prior to data collection approval was sought from various sisters-in-charge of the chosen clinics. Individual participants were then approached in their work settings by a trained research assistant. Potential participants were informed that participation was voluntary and that all responses would remain confidential. Each participant signed a written informed consent form prior to completing the survey. The structured questionnaire was interview-administered in English by one trained research assistant with a postgraduate qualification in psychology. A pilot study was conducted on six nurses who did not form part of the final sample to test the reliability of the interview-administered questionnaire. The same nurses (from the pilot study) were asked to respond to the interview schedule after 3 weeks. The responses from the first and second interview were comparable, and this is an indication of the reliability of the questionnaire.

\section{Measures}

On the basis of a literature review the following three measures, which have been used in other studies, have been included:

(1) A 16-items questionnaire on knowledge on health promotion. which aimed at examining the nurses' general knowledge about healthy lifestyle (Al-Shahri et al., 1997: 127). Responses were anchored from $1=$ strongly disagree to $5=$ strongly agree but in Table 1 strongly disagree and disagree as well as strongly agree and agree were grouped together. Cronbach alpha and split-half reliability were for the attitude measure .60 and .56 respectively.

An 8-items questionnaire, which assessed attitudes towards health promotion of specific lifestyles (AlShahri et al. 1997: 128). Responses were anchored from $1=$ strongly disagree to $5=$ strongly agree but in Table 3 strongly disagree and disagree as well as strongly agree and agree were grouped together. Cronbach alpha and split-half reliability were for the attitude measure .63 and .59 respectively. 
(3)

An 18-item "Nurses' Views of Health Promotion In terventions questionnaire" (Littlewood \& Parker, 1992: 88 ) including three areas of concern (two items: constraints; six items: responsibility, advocacy, and appropriateness of health promotion within the nursing role; and 10 items: patients' response to particular health promotion activities that may be initiated by the nurse. Participants were asked to reply on a 4-point Likert scale indicating agreement or disagreement with each item. However, in Table 2 responses on strongly disagree and disagree as well as strongly agree and agree were grouped together. Cronbach alpha and split-half reliability were for the attitude measure .65 and .58 respectively.

(4) Five items on sociodemographic characteristics: age, sex, year of graduation, additional qualifications, and attendance of training courses.

\section{Data analysis}

Data analysis included descriptive, comparative, t-test and correlational statistics using the Statistical Package for the Social Sciences for Windows (SPSS-PC, version 8.0).

\section{Results}

The nurse clinicians were 73 primary health care nurses and 17 midwives, 13 male (14.4\%) and 77 female $(85.6 \%)$ in the age range of 24 to 59 years ( $M$ age 38.4 yr., $S D=9.3$ ). The majority were registered nurses and 11 either had or were involved in obtaining a Degree in Nursing.

The number of years of nursing practice ranged from 1 to 32 years, with a mean of 9.2 years $(S D=9.3)$. Most nurses had attended various training courses such as on TB management (22.2\%), breast feeding (20\%), HIV counselling (16.7\%), primary health care $(14.4 \%)$, effective prescribing (13.3\%) and health for change (13.3\%).

The scores on the knowledge scale could range from 16 to 80 , and in this sample ranged from 40 to $72(M=61.4 ; S D=6.4)$, with only 30 nurse clinicians (33.3\%) achieving -with 64 plus scores- satisfactory knowledge scores. Pearson correlation showed that age $(r=-.065, \mathrm{~ns})$ as well as years of experience ( $r=-.072$, ns) were both not associated with the knowledge scale. The t-test showed significant associations between (male) gender $(t=-2.285, p<.025)$ but not area of specialization (primary health care or midwives) $(t=-.915$, ns), additional qualification (versus none) $(t=-1.099, \mathrm{~ns})$, continuing education attendance (versus none) $(t=-.151, \mathrm{~ns})$ and knowledge score of nurse clinicians.

\section{Table 1: Nurse clinicians ' knowledge about health promotion in percent $®=$ reverse scored for knowledge scale}

\begin{tabular}{|c|c|c|c|}
\hline Statement & \begin{tabular}{|l} 
Agree \\
$(\%)$
\end{tabular} & \begin{tabular}{|l|}
$\begin{array}{l}\text { Not } \\
\text { sure } \\
(\%)\end{array}$ \\
\end{tabular} & \begin{tabular}{|l|} 
Dis- \\
agree \\
$(\%)$ \\
\end{tabular} \\
\hline \multicolumn{4}{|l|}{ Cigarette smoking } \\
\hline $\begin{array}{l}\text { 1. Recent research doubted the association between smoking and lung } \\
\text { cancer } \mathbb{B}\end{array}$ & 24.4 & 13.3 & 62.2 \\
\hline 2. Passive smoking is always harmful & 91.1 & 2.2 & 6.6 \\
\hline $\begin{array}{l}\text { 3. Quitting smoking is not of major ben efit to a smoker for ten years' } \\
\text { duration }(B\end{array}$ & 26.7 & 5.6 & 67.8 \\
\hline 4. Smoking is associated with lung cancer but not with COPD (B) & 21.1 & 12.2 & 66.7 \\
\hline $\begin{array}{l}\text { 5. Children of a smoker are at risk of deve loping smoking-related } \\
\text { health problems }\end{array}$ & 91.1 & 1.1 & 7.8 \\
\hline \multicolumn{4}{|l|}{ Physical exercise } \\
\hline 1. For the non-obese, regular exercise is not highly reco & 27.7 & 2.2 & 70.0 \\
\hline $\begin{array}{l}\text { 2. Regular exercise is of great benefit to patients with coronary heart } \\
\text { disease }\end{array}$ & 51.1 & 5.6 & 33.3 \\
\hline 3. Physical exercise has no age limits & 90.0 & 1.1 & 8.9 \\
\hline $\begin{array}{l}\text { 4. Exercise three times or more per week on regular basis is better } \\
\text { than exercise less often }\end{array}$ & 80.0 & 6.7 & 13.4 \\
\hline $\begin{array}{l}\text { 5. For a better health and fitness, aerobic exercise is superior to } \\
\text { anaerobic }\end{array}$ & 64.5 & 28.9 & 6.7 \\
\hline 6. Walking and swimming are examples of aerobic exercises & 72.2 & 17.8 & 10.0 \\
\hline 7. Weight lifting is a form of anaerobic exercise & 15.5 & 28.9 & 55.5 \\
\hline \multicolumn{4}{|l|}{ Control of body weight } \\
\hline 1. Body mass index of 25 to 35 is considered normal $B$ & 16.6 & 60.0 & 23.4 \\
\hline $\begin{array}{l}\text { 2. There is a strong association between obesity and type II diabetes } \\
\text { mellitus }\end{array}$ & 84.4 & 10.0 & 5.5 \\
\hline $\begin{array}{l}\text { 3. Distribution of body fats has a role in determining the risk for some } \\
\text { diseases }\end{array}$ & 94.5 & 1.1 & 4.4 \\
\hline 4. Obesity is sometimes good for health $B$ & 10.0 & 0.0 & 90.0 \\
\hline
\end{tabular}


Table 1 indicates nurses' knowledge about cigarette smoking, physical exercise and control of body weight.

Between $62 \%$ to $91 \%$ of the nurse clinicians had adequate knowledge on cigarette smoking. While most nurses $(75.6 \%)$ recognized walking and swimming to be aerobic exercises, only about half (46.6\%) of the participants knew that weight lifting is a form of anaerobic exercise. Only about a quarter (23.4\%) of the nurse clinicians seemed to know the cut-off point for abnormal body mass index. However, the majority (90\%) saw the relationship between obesity and pathology. Table 2 indicates nurse clinicians' views about health promotion

\section{Table 2: Attitudes of nurse clinicians towards health promotion in percent}

\section{(B) = reverse scored scale}

\begin{tabular}{|c|c|c|}
\hline Statement & $\begin{array}{l}\text { Agree } \\
(\%)\end{array}$ & $\begin{array}{l}\text { Dis- } \\
\text { agree } \\
(\%)\end{array}$ \\
\hline \multicolumn{3}{|l|}{ Constraints } \\
\hline 1. I do not have enough time to carry out health promotion effectively & 56.5 & 43.6 \\
\hline $\begin{array}{l}\text { 2. Medical doctors do not have enough time to carry out health promotion } \\
\text { effectively }\end{array}$ & 62.9 & 37.0 \\
\hline \multicolumn{3}{|l|}{ Responsibilities } \\
\hline $\begin{array}{l}\text { 1. Medical doctors/nurses should be health advocates, insisting that } \\
\text { preventive health is put on the political agenda } \AA\end{array}$ & 93.0 & 7.1 \\
\hline 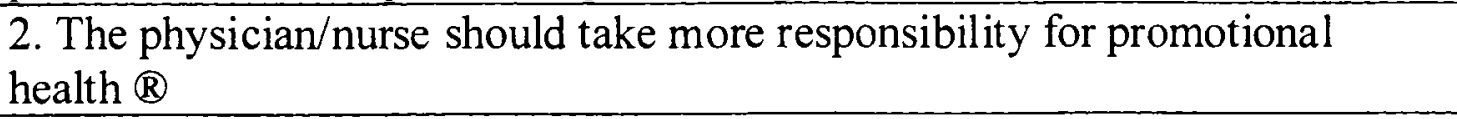 & 96.5 & 3.5 \\
\hline 3. The government should take more responsibility for promotional health ${ }^{\circledR}$ & 95.3 & 4.7 \\
\hline 4. Medical doctors are ideally placed to give health education to their clients & 92.9 & 7.1 \\
\hline 5. Nurses are more appropriate people to get involved in health promotion $(\AA$ & 96.5 & 3.6 \\
\hline 6. On the whole people have themselves to blame if they become ill & 43.6 & 56.5 \\
\hline \multicolumn{3}{|l|}{ Perception of clients responses } \\
\hline 1. Clients find health education dull and boring & 55.3 & 44.7 \\
\hline 2. I find health education dull and boring & 7.1 & 92.9 \\
\hline 3. Health education is guilt inducing and victim blaming & 37.6 & 62.3 \\
\hline $\begin{array}{l}\text { 4. The evidence relating diet to health is too uncertain and contradictory for } \\
\text { me to advise my patients on what to eat }\end{array}$ & 9.4 & 90.6 \\
\hline $\begin{array}{l}\text { 5. Nurses should not interfere with people's lives by telling them to stop } \\
\text { smoking, lose weight, or do more exercise }\end{array}$ & 4.7 & 95.3 \\
\hline $\begin{array}{l}\text { 6. People's lifestyles are conditioned by their culture and environment; } \\
\text { there's not much a professional can do to change them }\end{array}$ & 34.1 & 65.9 \\
\hline 7. In general people do not take any notice of what nurses say on lifestyle & 34.1 & 65.8 \\
\hline $\begin{array}{l}\text { 8. Giving detailed explanations to patients tends to worry them rather than } \\
\text { reassure them }\end{array}$ & 47.1 & 53.0 \\
\hline $\begin{array}{l}\text { 9. Helping people to understand how their bodies work is an important part } \\
\text { of health care } \mathbb{B}\end{array}$ & 90.6 & 9.4 \\
\hline $\begin{array}{l}\text { 10. Clients get annoyed when I ask them if they smoke, when smoking is not } \\
\text { directly related to their presenting health problems }\end{array}$ & 61.2 & 38.8 \\
\hline
\end{tabular}


selves if they become ill.

Just over half of the nurses and midwives (55.3\%) reported that they perceived that clients find health education dull and boring and more, and more than one-third (37.6\%) viewed health education as guilt inducing and victim blaming. On the other hand, almost all nurses $(95.3 \%$ ) disagreed that counselling against smoking, promoting weight reduction, and encouraging exercise constituted ,interference“ in the lives of patients, and on the other hand many nurses $(61.2 \%)$ agreed that patients will get annoyed when being asked about smoking, when smoking is not directly related to their presenting health problems, $34 \%$ agreed that lifestyles are so influenced by culture and environment that there is ,not much a professional can do to change them," and $34 \%$ agreed that clients do not take any notice of what nurses say related to lifestyle. A positive perception score towards health promotion was created, the scores could range from 18 to 72 , and in this sample it ranged from 46 to $68(M=56.0 ; S D=5.0)$, with 57 nurses $(63.3 \%)$ achieving -with 54 plus scores- satisfactory perception scores. Pearson correlation showed that age $(\mathrm{r}=-$ $.088, \mathrm{~ns})$ as well as years of experience $(\mathrm{r}=-.052, \mathrm{~ns})$ were both not associated with the perception scale. The t-test showed a significant association between gender (men) $(t=-2.910$, $p<.005$ ) but not area of specialization (primary health care or midwives) $(t=-.836, \mathrm{~ns})$, additional qualification $(t=-.682, \mathrm{~ns})$ and continuing education attendance (versus none) ( $t=-1.075$, ns) with the perception score of nurses.

Knowledge about health promotion was significantly associated with a positive perception towards health promotion among the nurses studied $(r=.217, p<.040)$.

Nurses seemed to be more negative than positive in changing patients' habits regarding exercise, controlling body weight. use of seat belts, and smoking, in that order. However, the majority felt that counselling about health promotion was cost effective, e.g. exercise (64.4\%), controlling body weight $(61.1 \%)$, use of seat belt $(53.3 \%$ ) and smoking $(53.3 \%)$ (see Table 3).

\section{Discussion}

Generally, nurses (66.6\%) had an inadequate knowledge score on health promotion in this sample. This is cause of concern. Higher knowledge scores on health promotion were not associated with age and years of experience. This seems to indicate that among the young generation of nurses not more emphasis is placed on health promotion than it was among older generations. However, male nurses had significantly higher knowledge scores on health promotion than female nurses. This may partly be explained by the more frequent use of cigarette smoking and exercise among men than among women. It was surprising that additional qualifications, area of specialization and training courses did not significantly contribute to the health promotion knowledge score. This finding may suggest to also include health promotion training in further training of nurses. Coulson (1999: 10f.) noted a capacity gap for health promotion in South Africa. This gap is primarily about having inadequate training opportunities. Furthermore, there was a strong sense that health promotion teaching to all health workers in their basic and post qualification training should be be strengthened.

The majority strongly supported the centrality of their role in health promotion acknowledging the time constraints involved. In addition, the role of the government in health promotion was emphasised. These results concur with findings among British community nurses (Littlewood \& Parker 1992: 89) and primary health care nurses and midwives in Jordan (Haddad \& Umlauf 1998: 524f.). There seemed to be a conflict between the nurses' own perception on health education as not dull and boring (92.9\%) and the nurses' perception that clients find health education dull and boring $(55.3 \%)$. This is supported by the perceived unimportance of what nurses say about lifestyle $(34.1 \%)$, the intertwinedness between lifstyles and culture and environment (34.1\%), and people should be blamed for becoming ill themselves (43.6\%). The question is whether health education needs to become more attractive to patients or whether the nurses' victim blaming attitudes need to be corrected. Studies with patients could clarify these aspects. Nurses further perceived their lifestyle

\section{Table 3: Nurse clinicians' attitudes towards specific health promotion in percent}

\begin{tabular}{|l|l|l|l|}
\hline $\begin{array}{l}\text { Most nurses feel helpless when it comes to changing patients' habits } \\
\text { regarding: }\end{array}$ & $\begin{array}{l}\text { Agree } \\
(\%)\end{array}$ & $\begin{array}{l}\text { Not } \\
\text { sure } \\
(\%)\end{array}$ & $\begin{array}{l}\text { Dis- } \\
\text { agree } \\
(\%)\end{array}$ \\
\hline a) Smoking & 47.7 & 0.0 & 52.2 \\
\hline b) Body weight & 31.1 & 4.4 & 64.5 \\
\hline c) Exercise & 28.8 & 3.3 & 67.8 \\
\hline d) Use of seat belts & 22.2 & 24.4 & 53.3 \\
\hline $\begin{array}{l}\text { Counselling about the following topics is not cost effective when } \\
\text { compared to the time and effort it takes: }\end{array}$ & & \\
\hline a) Smoking & 44.5 & 2.2 & 53.3 \\
\hline b) Body weight & 35.5 & 3.3 & 61.1 \\
\hline c) Exercise & 30.0 & 5.6 & 64.4 \\
\hline d) Use of seat belts & 23.4 & 23.3 & 53.3 \\
\hline
\end{tabular}


education such as on smoking -similarly to primary health nurses in Jordan (Haddad \& Umlauf 1998: 523)- as annoying for the patient $(61.2 \%)$, guilt inducing and victim blaming $(37.6 \%)$, and worrysome if giving detailed explanations $(47.1 \%)$. This perception of nurses that patients may resent their advice may hinder them from carrying out opportunistic health promotion (Littlewood \& Parker 1992: 89). In contrast, very few South African (4.7\%) and Jordanian nurses $(8.6 \%)$ believed that nurses should not interfere with client's lives by telling them to stop smoking, lose weight, or do more exercise (Haddad \& Umlauf 1998: 526). This may mean that nurses feel the responsibility for health promotion but are at the same time aware of the possible resentment of patients, which may be more appropriately addressed by using a health rather than a risk or disease approach of health promotion.

Not surprising was that better knowledge on health promotion was associated with more positive views on health promotion. However, more nurses had a satisfactory positive attitude towards health promotion $(63.3 \%)$ than knowledge about health promotion $(33.3 \%)$. It was surprising that additional qualifications, area of specialization and training courses did not significantly contribute to a more positive perception about health promotion.

This study found that compliance with health promotion was seen as a problem but health counselling was nevertheless seen as cost effective.

Further, the study revealed that male nurses reported more knowledge and a more positive perception about health promotion than female nurses, which needs further investigation.

Limitations of the study include that the sample is limited to one of the provinces in South Africa and that one cannot generalize the findings to the whole of South Africa. Moreover, the actual health promotion practices of the nurses were not assesed and could be subject to a further study.

Recommendations include improving the knowledge on health promotion among nurses in the Northern Province in South Africa by placing more emphasis on health promotion during the professional training and on-job training of nurses. The attitude of nurses that patients find health education boring and interfering needs to change and possibly health promotion activities of nurses may have to be done more appealing and persuasive to patients using a health rather than a risk or disease approach of health promotion.

\section{Acknowledgement}

The financial assistance of the National Research Foundation (South Africa) towards this research is hereby acknowledged. Opinions expressed this publication and conclusions arrived at, are those of the author and are not necessarily to be attributed to the National Research Foundation.

\section{References}

AL-SHAHRI, M Z; AL-ALMAEI, SM \& MIAN, M H 1997: Promotion of healthy lifestyle: knowledge and attitudes of primary care physicians. Patient Education and Counseling. 31: 125-130.

BRADSHAW, D; BOURNE, DE, SCHNEIDER, M \& SAYED, R 1995: Mortality patters of chronic diseases of life style in South Africa. (In: Furie, J, \& Steyn, K. eds. Chronic diseases of life style in South Africa, pp. 5-36). Cape Town: MRC Technical Reports.

COULSON, N 1999: Health promotion. South African Health Review. 1999. Chapter 21.

COULSON, N; GOLDSTEIN, S \& NTULI, A 1998: Promoting health in South Africa: an action manual. Sandton: Heineman.

DEPARTMENT OF HEALTH 1997: White Paper on Health Systems Transformation. Pretoria: Department of Health.

HADDAD, LG \& UMLAUF, MG 1998: Views of health promotion among primary health care nurses and midwives in Jordan. Health Care for Women International. 19: 515528.

LITTLEWOOD, J \& PARKER, 1 1992: Community nurses' attitudes to health promotion in one regional health authority. Health Education Journal. 51: 87-89.

MEDICAL RESEARCH COUNCIL (SOUTH AFRICA) 1998: South Africa demographic and health survey. Pretoria: Department of Health.

NORTON, L 1998: Health promotion and health education: what role should the nurse adopt in practice? Journal of Advanced Nursing. 28: 1269-1275.

SOURTZI, P 1998: Defining health promotion: the view of community nurses. International Journal of Health Education. 36: 9-14.

STEPTOE, A \& WARDLE, J 1992: Cognitive predictors of health behaviour in contrasting regions of Europe. British Journal of Clinical Psychology. 31: 485-502.

STEPTOE, A; DOHERTY, S; KENDRICK, T; RINK, E \& HILTON, S 1999: Attitudes to cardiovascular health promotion among GPs and practice nurses. Family Practitioner. 16: $158-163$.

WHITEHEAD, D 2001: Health education, behavioural change and social psychology: nursing's contribution to health promotion? Journal od Advanced Nursing. 34: 822-832.

WORLD HEALTH ORGANIZATION 1986: Ottawa Charter for Health Promotion. Copenhagen: WHO.

WORLD HEALTH ORGANIZATION 1999: Primary Health Care. Geneva: WHO. 